\title{
National implementation plan for MON810 monitoring in Germany - A way forward to improve General Surveillance?
}

\author{
A. Gathmann \\ Federal Office for Consumer Protection and Food Safety (BVL), Berlin, Germany \\ Correspondence to: Dr. Achim Gathmann, Federal Office for Consumer Protection and Food Safety (BVL), \\ Mauerstr. 39-42, D-10117 Berlin, Germany, \\ Tel. +49 3018444 40410, E-mail: Achim.Gathmann@bvl.bund.de
}

With respect to the renewal procedure of MON810 authorization, Monsanto submitted a MON810 monitoring plan (MP) according to the conditions of Directive 2001/18/EC to the EU Commission in May 2007. However, the conditions for MON810 authorization of 1998 (without MP) are still valid unless a decision on renewal is taken. In April 2007, the responsible German Competent Authority (Federal Office for Consumer Protection and Food Safety - BVL) took action for guaranteeing the implementation of the new submitted MP of 2008, independently of the duration of the renewal process. Thereupon Monsanto submitted a concept for national implementation of the new MP in Germany (BVL, 2007). Monsamto's new MP is based on four monitoring tools: (i) analysis of scientific literature, (ii) stewardship program of the applicant, (iii) questionnaires for farmers and processors and (iv) publicly available information of existing environmental monitoring systems. The national implementation plan focuses on the strategy to identify useful monitoring programs for General Surveillance. This identification process is based on a general list of existing environmental monitoring programs in Germany provided by the BVL. The applicant developed criteria for the selection of useful environmental monitoring programs. The main criteria are regional reference, used methodology and data quality, correlation with protection goals, interplay with other elements of monitoring, frequency of data collection, and public availability of data or reports. Monsanto identified seven monitoring programs as suitable and will evaluate the publicly available information of these programs within their monitoring scheme. The BVL acknowledged in December 2008 that the national implementation of the MON810 MP is satisfying until the renewal process is completed. However some difficulties in practical implementation still have to be overcome in the future, such as different understanding of General Surveillance among participating stakeholders, communication problems, and methodical challenges.

\section{Literature}

BVL (2007) Erläuterungen zu Monitoring und Implementierung von MON810. http://www.bvl.bund.de/cln_027/DE/08__PresseInfothek/00_doks_downloads/Monitoringplan,templateId=raw,property=publicationFile.pdf/Monitoringplan.pdf (in German and English language).

Directive 2001/18/EC of the European Parliament and of the Council on the deliberate release into the environment of genetically modified organisms and repealing Council Directive 90/220/ EEC. Official J European Communities 17.04.2001, p. No L 106/1

To access this journal online:

http://www.birkhauser.ch/JVL 